\title{
Resident Teaching Expectations and Medical Student Feedback
}

Michael Ignatowski

Wright State University - Main Campus, mi305302@ohio.edu

Follow this and additional works at: https://jdc.jefferson.edu/jeffjpsychiatry

Part of the Psychiatry Commons

Let us know how access to this document benefits you

\section{Recommended Citation}

Ignatowski, Michael (2010) "Resident Teaching Expectations and Medical Student Feedback," Jefferson Journal of Psychiatry. Vol. 23 : Iss. 1 , Article 2.

DOI: https://doi.org/10.29046/JJP.023.1.002

Available at: https://jdc.jefferson.edu/jeffjpsychiatry/vol23/iss1/2

This Article is brought to you for free and open access by the Jefferson Digital Commons. The Jefferson Digital Commons is a service of Thomas Jefferson University's Center for Teaching and Learning (CTL). The Commons is a showcase for Jefferson books and journals, peer-reviewed scholarly publications, unique historical collections from the University archives, and teaching tools. The Jefferson Digital Commons allows researchers and interested readers anywhere in the world to learn about and keep up to date with Jefferson scholarship. This article has been accepted for inclusion in Jefferson Journal of Psychiatry by an authorized administrator of the Jefferson Digital Commons. For more information, please contact: JeffersonDigitalCommons@jefferson.edu. 


\section{Resident Teaching Expectations and Medical Student Feedback}

Michael Ignatowski, D.O., (PGY4), Brenda Roman, M.D., Pavan Somusetty, M.D., David Bienenfeld, M.D. 


\begin{abstract}
Objective

Much of resident teaching of medical students occurs in an informal manner, with bedside teaching a common focus. Hence, the ability to monitor such teaching is limited. Feedback about how students perceive the teaching is perhaps one way to more effectively monitor and influence resident teaching.
\end{abstract}

\title{
Methods
}

A "residents as teachers" program is described that includes specific resident teaching expectations. Students give feedback on whether the residents met these expectations; resident evaluations are reviewed by the Director of Medical Student Education and utilized by the Residency Training Director in the semi-annual resident reviews. 


\section{Results}

Over the last two years, student satisfaction regarding teaching from residents during the psychiatry clerkship has greatly improved.

\section{Discussion}

Through providing specific resident teaching expectations, and with mechanisms in place to monitor teaching efforts, including the use of regular feedback to residents, student satisfaction with resident teaching can improve.

Preparing residents as educators of medical students is required by the Liaison Committee on Medical Education. (1) Additionally, residency requirements also mandate that residents be prepared for their roles as educators. (2) Teaching activities may consume about $20 \%$ of their time in any given day. (3) One study found that medical students estimated that about $30 \%$ of their knowledge could be directly attributed to resident teaching. (4) Additionally, residents feel that through teaching students, they also learn more, especially about the assigned teaching topics. (5) 
However, a wide variation of training for these roles exists, from "residents as teachers" programs during internship orientation to month long electives.

(6) Little is written in the literature about consistently incorporating teaching feedback by the medical students, and on developing programs to improve individual teaching abilities. Morrison et al, found in a 2001 survey that only about $55 \%$ of residency programs offered formal training in teaching skills, most often in internal medicine and pediatrics programs. (7) Perhaps, this explains why internal medicine and pediatrics clerkships had the lowest rates of dissatisfaction regarding resident teaching in the American Association of Medical Colleges (AAMC) annual graduation questionnaire (GQ). (8) The AAMC GQ reinforces that residents do not always provide the most effective teaching, with ranges from $10.1 \%$ for no opinion/disagree/strongly disagree in the internal medicine national average to a high of $31.9 \%$ in the obstetrics and gynecology national average concerning the statement "Residents and fellows provided effective teaching during the clerkship." Psychiatry also showed that $26.7 \%$ of students nationally were not satisfied with resident teaching during the clerkship. (8) Despite these numbers, residents are often identified by medical students as being the most influential teachers. (9) Additionally, residents serve as role models for students, especially in modeling values and professionalism. (10) 
Given the importance of resident teaching, there are surprisingly few papers that evaluate the outcomes of these programs. Wamsley et al. in a 2004 literature review found only 14 outcome evaluations of residents as teachers programs, with the following findings: that these courses improved residents' self assessed behaviors and teaching confidence and resulted in higher learner evaluation of residents. (11) A 2005 randomized controlled study by Morrison et al, examined differences in objective structured teaching examinations (OSTE's) pre/post a teaching curriculum vs. a control group who did not participate in the curriculum, and found that those residents completing the 13 hours of teacher training had greater enthusiasm for teaching, utilized more learner-centered approaches to teaching and had a richer understanding of clinical teaching principles and skills. (12) A 2008 Canadian study of pediatric training programs found that training directors generally felt that residents needed more training in providing feedback; while residents wanted more guidance in bedside teaching. They also found that residents were generally uncertain of expectations and assessment methods. (13)

In recent years, attention has focused on the concepts of the formal, informal and hidden curriculum in medical education, especially as it relates to professionalism and ethics. Hafferty defines the formal curriculum as 
"the stated, intended and formally offered and endorsed curriculum"; the informal curriculum as the "unscripted, predominantly ad hoc and highly interpersonal form of teaching and learning that takes place among and between faculty and students"; and the hidden curriculum as "a set of influences that function at the level of organizational structure and culture".

(14) As noted by Ozolins, there is little attention to the informal learning that occurs with students and how that may help them address the formal curriculum. (15) Several authors have noted that inconsistencies exist between aspects of the formal curriculum and the actual clinical experiences of students. $(16,17,18)$ Only one study has examined this concept in a psychiatry clerkship. (19) Wear conducted focus groups of students, residents and attendings, finding themes that emerged around role modeling, time (with the theme that there was often not enough time for either teaching or patient care), and the curriculum as based more on experience and intuition vs. textbook learning. (19) Most interestingly, residents and students cited both positive and negative examples in each of these themes, whereas faculty primarily gave positive examples. This is similar to the findings by Adler, in which the study found that faculty may be unaware of how their curriculum is experienced by students. (20) 
After instituting a position of Education Chief Resident for Medical Student Education in 2007, as well as the Director of Medical Student Education (DMSE) meeting individually with students for a mid-clerkship session, it was apparent that discrepancies existed in our program between the formal curriculum and the informal and hidden curriculum. To address this issue, the "resident as teachers" program was expanded to include mechanisms to communicate more clearly to residents the teaching expectations as well as addressing with the residents the issues of the hidden and informal curriculum, utilizing feedback from the students.

\section{Methods}

Historically, some residents do a great job teaching medical students, being intrinsically motivated to assist students through observing their interviews, providing feedback on their skills, reviewing notes and giving mini-lectures to assist them in their program of study. However, other residents have an attitude that medical students are simply there to assist in their clinical work, or even worse, view them as a hassle and show no interest in teaching. Thus evaluations of resident teaching vary greatly 
amongst the students, largely dependent on an individual resident's motivation to teach. Furthermore, some residents may simply not know the expectations for a clerkship teaching. At the same time as the Education Chief Resident for medical student education position was being developed in 2007, the entire "residents as teachers" teaching program was revamped, with linkage of the clerkship objectives to resident teaching duties, development of resource material for residents to utilize in their teaching, and increased supervision of the residents regarding medical student teaching. Besides the Education Chief Resident position, generally 2 residents a year take a senior elective in medical student teaching, devoting a half day a week to teaching the medical students on the inpatient units.

The "residents as teachers" program now includes an hour of introduction to medical student teaching during orientation week given by the DMSE and the Education Chief Residents. In this session, the PGY-I residents are given the educational objectives of the clerkship for the medical students, the specific resident expectations in teaching on the clerkship, a teaching handbook developed by the DMSE, and information about the evaluation process by the medical students of resident teaching. The Education Chiefs present the top "Do's and Don'ts" of teaching medical students, utilizing audio-visual segments from various medical television 
shows. We also invite the residents, who were students just a few months prior, to share what they found useful as residents taught them. They generally identify a passion for teaching, spending time with students answering their questions and giving feedback on clinical skills as the most important aspects of teaching medical students. We also introduce the concepts of the hidden and informal curriculum as a way to begin to get them thinking about messages that residents and attendings may inadvertently be giving medical students. Residents quickly identify stigmatizing comments of psychiatric patients as one area of concern.

Later in the internship year, after the residents have had exposure to medical student teaching and are more comfortable with their own clinical skills; the residents have a 4 week didactic series on medical student teaching, which includes information on adult learning theory, providing effective feedback, and working with challenging students.

A Handbook of Medical Student Education was developed to illustrate learning theories, provide teaching guidelines and expectations, give strategies for feedback, and outline steps to take in difficult situations. Limited to less than 10 pages in length, it is given to each resident in the program to serve as a guide for the residents in their medical student teaching responsibility. 
Specific resident expectations in teaching were also developed. These expectations include demonstrating professionalism in all aspects of interactions with patients, residents and other students, to include refraining from criticizing other residents or students in front of students. Residents are expected to become familiar with the academic requirements for the students, thus are given the learning objectives for the psychiatry clerkship, and have access to the clerkship website to view materials. At the beginning of the rotation, residents are expected to allow a student to observe the interview, and then present the case to the students. In this way, they can then model the expected format. Subsequently, residents are expected to observe at least one interview, hear the student presentation of the case, and provide constructive feedback. At least once a week, residents are to provide verbal feedback on student progress notes and other documentation in the medical record. They are to also make themselves available for questions, and to focus on clinical education whenever possible.

The evaluation process for residents as teachers includes an electronic evaluation of individual residents as teachers, which the students complete at the end of their rotation. Additionally, the education chief meets with all of the students at the end of the rotation to review whether or not each resident met the teaching expectations. This checklist [See Table 1] covers areas of 
whether they were observed by a resident doing an interview, whether feedback was given to them on written notes, if adequate teaching occurred, and if there were any professionalism concerns. These evaluations are given to the DMSE and the residency training (RT) director for review. The RT director uses this information in his semi-annual reviews of the residents, thus emphasizing the importance of medical student teaching. If an urgent issue arises, the RT director and DMSE discuss the nature of the concerns, and decide how to address the issue. By doing this together, the residents know that teaching is a highly valued part of their residency education program.

Most importantly in our resident as teachers program, we pay close attention to the hidden informal curriculum in our evaluation and feedback process. In the meetings with the DMSE, students are invited to discuss concerns about residents, or attendings, as well as any conflicting values seen between the formal curriculum and the residents and attendings, and the general educational environment. Invariably, students express their observations that while the formal didactic curriculum focuses on the psychological issues of patients, they often see the issue of time driving treatment decisions; therefore, psychopharmacology is emphasized over other treatment modalities. Thus we are able to discuss some of the 
competing ethical issues in academia. Throughout the academic year the Education Chief meets with the junior residents to discuss any concerns that they might have regarding students or problems that they need assistance in solving. Residents often asked for clarification on the clerkship objectives and grading process to better understand what the students need. Some issues that came up included how to handle breaches in professionalism on the part of a resident or student. They also discussed how to reinforce the formal curriculum in spite of the limitations on the wards due to lack of time or conflicting messages from attendings or other residents.

\section{Results}

Individual responses concerning feedback for resident teaching provided by the students varied from resident to resident (See Table 1). The responses provided by the medical students cannot be compared to previous years since this feedback form was recently instated, and the questions were not asked of previous years students. The utility of asking such questions of the medical students is to let the residents know what is expected of them in regards to student teaching and professionalism. 
Data is limited since the clerkship evaluations utilized by the School of Medicine only asks one question regarding the effectiveness of resident teaching; however, available data indicate that our efforts have definitely improved the teaching of medical students by the resident. Post clerkship evaluations reveal student satisfaction with resident teaching has increased significantly since these measures have been instituted from averages of 3.67 and 3.95 (out of 5 with 5 being highly satisfied) in the 2 academic years prior to changes in the medical student teaching program to averages of 4.20 in the last academic year and 4.37 for this current year.

The effectiveness of the changes made is also demonstrated in the AAMC Graduation Questionnaire of Medical Students which inquires if the residents and fellows provided effective teaching during the clerkship. The satisfaction of the students has gone up consistently over the past 2 academic years, from $81.3 \%$ in 2007 , to $86 \%$ in 2009 . This can be compared to the 2009 national average of $72 \%$. Furthermore, the percentage of students who strongly agreed that the residents provided effective teaching went up from $33.3 \%$ in 2007 , to $40.7 \%$ in 2009 . The 2009 national average of students who strongly agree is $30.6 \%$. (21) 


\section{Discussion}

Teaching of medical students by residents has improved considerably; however efforts must continue to address the core skills. While students report greater satisfaction, we do not currently have other objective measures in place to examine the quality of teaching, nor the content. On occasion, students will argue about missed questions on quizzes as "residents told me that the answer is always ..." even when the textbook and other evidence based reviews indicate that the students had received inaccurate information from the residents. Since such information can be due to the "trickle down" effect coming from an attending psychiatrist, it is crucial for attendings to keep current with evidenced based psychopharmacology. The biggest challenge occurs in the context of attitudes and behaviors by residents who may not be modeling the best professionalism for the students; examples that students have commented about include residents who come across as arrogant and hierarchical, who are having conflicts with other residents and who are overly rigid in their approach to teaching. In cases where feedback from students in more than one rotation observes such behaviors, the 
residents are made aware of the perceptions by the students. Invariably, the residents either were not aware of how they were coming across or in a minority of cases, view their style as part of the hierarchical nature of medicine. Most residents respond to the feedback so it is generally not a concern expressed by students again.

\section{Future Directions}

Residents have been primarily receiving supervision about teaching students from the senior residents; in this current academic year, a weekly supervision conference has been added for junior residents to discuss any concerns that they are having regarding students, with a focus on the most effective ways to address such concerns. This conference is led by the DMSE, with participation from the Education Chief Residents and the training director. In the coming academic year, in light of the recent critical review regarding the effectiveness of residents-as-teachers curricula, an early didactic session explaining the One-Minute-Preceptor methodology will be given to incoming residents, with quarterly spaced education emails concerning the methodology. (22) We are also interested in examining the results of the 2010 AAMC Graduation Questionnaire to determine how 
much our efforts continue to impact student satisfaction with resident teaching, as well as the overall psychiatry clerkship satisfaction.

At the time of this submission, the authors disclosed no competing interests.

\section{Source Information}

From the Wright State University Boonshoft School of Medicine Department of Psychiatry Address reprint requests and correspondence to Brenda Roman, M.D. University Boonshoft School of Medicine Department of Psychiatry. 627 S. Edwin C. Moses Blvd. Dayton, Ohio 45417-1461

\section{References}

1. Liaison Committee on Medical Education. (Accessed February 28, 2010, at http://www.lcme.org/functionslist.htm.)

2. Accreditation Council for Graduate Medical Education. (Accessed

February 28, 2010, at

http://www.acgme.org/acWebsite/downloads/RRC_progReq/400_psychiatry _07012007_u04122008.pdf .) 
3. Greenberg LW, Goldberg RM, Jewett SL. Teaching in the clinical setting; factors influencing residents' perceptions, confidence and behavior. Med Educ 1984; 18:360-365

4. Bing-You RG, Sproul MS. Medical students' perceptions of themselves and residents as teachers. Med Teach 1992; 14:133-138

5. Weiss V, Needlman R. To teach is to learn twice: resident teachers learn more. Arch Pediatr Adolesc Med 1998; 152:190-192

6. Mann KV, Sutton E, Frank B. Twelve tips for preparing residents as teachers. Med Teach 2007; 29:301-306

7. Morrison EH, Friedland JA, Boker J, et al. Residents-as-teachers training in the U.S.: residency programs and offices of graduate medical education. Acad Med 2001; 76(10 Suppl):S1-S4

8. American Association of Medical Colleges: AAMC Graduation Questionnaire of Medical Students. 2008. (Accessed February 28, 2010, at http://www.aamc.org/data/gq/questionnaires/start.htm.)

9. Morrison EH, Hollingshead J, Hubbell FA, et al. Reach out and teach someone: generalist residents' needs for teaching skill development. Fam Med 2002; 34: 445-450

10 Stern D. Practicing what we preach? An analysis of the curriculum of values in medical education. Am J Med 1998; 104:569-575 
11. WamsleyM, Julian K, Wipf J. A literature review of 'resident-asteacher' curricula. J Gen Intern Med 2004; 19:574-581

12. Morrison EH, Shaprio JF, Harthill M. Resident doctors understanding of their roles as clinical teachers. Med Educ 2005; 39:137-144

13. Walton JM, Patel H. Residents as teachers in Canadian pediatric training programs: A survey of program director and resident perspectives. Paediatr Child Health. 2008; 13 (8):675-679

14. Hafferty FW, Frank R. The hidden curriculum, ethics teaching and the structure of medical education. Acad Med 1998; 69:861-871

15. Ozolins I, Hall H, Peterson R. The student voice: Recognizing the hidden and informal curriculum in medicine. Med Teach 2008; 30:606-611 16. Hicks LK, Lin Y, Robertson DW, et al. Understanding the clinical dilemmas that shape medical student ethical development: Questionnaire survey and focus group study. Br. Med J 2001; 322:709-710

17. Fins JJ, Gentilesco BF, Carver A, et al. Reflective practice and palliative care education: A clerkship responds to the informal and hidden curricula. Acad Med. 2003; 78(3):307-312

18. Aultman JM. Uncovering the hidden medical curriculum through a pedagogy of discomfort. Ad Health Sci Edu 2005; 10(3):263-273 
19. Wear D, Skillicorn J. Hidden in Plain Sight: The formal, informal, and hidden curricula of a psychiatry clerkship. Acad Med 2009; 84:451-458

20. Adler SR, Hughes EF, Scott RB. Student "moles": Revealing the hidden curriculum. Med Educ 2006; 40(5):463-464

21. American Association of Medical Colleges: AAMC Graduation Questionnaire of Medical Students. 2009. (Accessed February 28, 2010, at http://www.aamc.org/data/gq/questionnaires/start.htm.)

22. Post RE, Quattlebaum GR, Benich J. Residents-as-teachers curricula: A Critical review. Acad Med 2009; 84:374-380 


\section{Table 1.}

\section{Resident Expectations for Medical Student Teaching Checklist}

YES___ NO___ The resident demonstrated respect and maintained a professional attitude with students throughout the rotation.

YES___ NO___ The resident worked through the assessment and plan on the majority of new admissions, allowing the student to present his/her differential diagnosis and plan, and discussed the rationale behind the final assessment and treatment plan, paying special attention to medication choices.

YES___ NO____ I observed the resident as he/she interviewed a patient to obtain a complete history early in the rotation, with the resident doing a presentation to model expectations for me as a student.

YES___ NO___ I was observed at least once early in the rotation by the resident, interviewing a patient to obtain a complete history and given immediate constructive criticism.

YES___ NO___ My admission notes and progress notes were regularly read by the residents, with constructive feedback given to me about my documentation.

YES___ NO___ The resident was available to answer general questions pertaining to diagnostics, medications, patient interactions, or other pertinent matters.

YES___ NO___ In rounds, I was allowed to complete my presentation through the assessment and plan to the greatest extent possible. After rounds, the resident provided feedback as to which aspects of the presentation were well done and which needed improvement.

YES__ NO___ I I was provided timely and constructive feedback on an individual basis by the resident.

YES__ NO___ The resident provided ward didactic topics and was an effective educator.

Comments: 